\title{
IMPACT OF THE INVASIVE PLANT ALTERNANTHERA PHILOXEROIDES (MART.) GRISEB ON SOIL MESO- AND MICROFAUNAL COMMUNITY
}

\author{
ZHANG, Z. ${ }^{1,2^{*}}-$ LIU, J. ${ }^{1}-$ WANG, L.-C. ${ }^{1}-$ WANG, Y. ${ }^{1}-$ DENG, L.-L. ${ }^{1}$ \\ ${ }^{1}$ College of Resources and Environment, Anhui Agricultural University, Hefei 230036, Anhui, \\ China \\ ${ }^{2}$ Hefei Scientific Observing and Experimental Station of Agro-Environment, Ministry of \\ Agriculture, P. R. China, Hefei 230036, China \\ *Corresponding author \\ e-mail:xjzhangzhen@163.com \\ (Received $2^{\text {nd }}$ Aug 2019; accepted 21 $1^{\text {st }}$ Jan 2020)
}

\begin{abstract}
Alternanthera philoxeroides (Mart.) Griseb is a plant species which has become one of the most damaging weeds in ecosystems. We examined potential effects of the invasive plant $A$. philoxeroides on soil animal community by considering four levels of plant invasion (including noninvaded, slightly invaded, moderately invaded and heavily invaded ecosystems) in Nanfeihe, Hefei, China. The following conclusions: A total of 2406 individuals of soil animals, belonging to 25 families, 13 orders and 7 classes, and Acarina and Collembola accounted for $64.52 \%$ of the total amount of soil animals captured, thus comprising the dominant species; Individual number of soil animals varied with different rate of invasion; the diversity and evenness indices of the soil fauna showed a pattern of noninvaded < heavily invaded $<$ moderately invaded $<$ slightly invaded, however, there were no significant differences between the moderately and slightly invaded plots. The vertical distribution of the species number and individual number of soil fauna had obvious surface segregation with the increased soil depth; The degree of invasion affects the soil physicochemical properties, and the total potassium content is significantly correlated with the number of soil fauna groups.
\end{abstract}

Keywords: biological invasion, exotic plant invasion, Alternanthera philoxeroides, soil meso- and macrofaunal, community diversity, Nanfeihe

\section{Introduction}

Biological invasion is a worldwide ecological phenomenon. Invasive species breed, reproduce, spread and form a stable population. Among them, exotic plant invasion, as an important group of invasive organisms, has seriously affected the biodiversity of the invaded land and the quality of the ecological environment, threatening the global ecological environment and economic development and have aroused worldwide concern, becoming one of the hot spots in global change research (Hui et al.2017).

In recent years, with the continuous increase in our understanding of soil ecosystem processes, research has focused on the impact of invasive plants on soil physicochemical properties, soil biodiversity and ecosystem processes, while soil fauna under the effect of invasive mechanisms has not been researched to such an extent (Yu et al., 2012; Pablo et al., 2014; Fernández et al., 2015; Nicola et al., 2015). Most studies have shown that the invasion of plants will increase the species and number of soil animals. Belnap et al. (2001) compared the numbers of invertebrates in early Brome intrusions and native Bromegrass in Utah, and found that species diversity and abundance were significantly reduced. Soil fauna, an important component of the soil ecosystem, can influence the soil environment through physical and chemical activities. Physical activities include plant 
debris crushing and decomposition, loosening and mixing of soil; The chemical activities include changing soil texture, crumb structure, aeration, water permeability and other physical properties, and influencing the soil $\mathrm{pH}$, organic matter, carbon and nitrogen content and other chemical elements (Yin, 2000). Soil fauna play an important role in plant community succession and soil nutrient cycling (Shao et al., 2015) and some soil animals can also be used to monitor environmental pollution as indicator organisms (Xiang et al., 2007). The spatial distribution and community diversity of soil fauna are of great significance in assessing ecological health, and are important targets in the study of soil ecosystems (Ding et al., 2017)

The exotic plant invasion of Alternanthera philoxeroides (Mart.) Griseb, originated from South America, is now widely distributed in the United States, Australia, New Zealand, China and many other countries by virtue of its adaptability, rapid spread and vegetative reproduction (Van et al., 2002). A. philoxeroides in China was first introduced as horse feed in the 1930s and is now widely distributed in most parts of China (Zhou et al., 2017). Through investigating the effect of different rates of invasion by $A$. philoxeroides on soil faunal and soil physicochemical properties, this study aimed to improved our knowledge the impact of this invasive plant on the belowground compartment of terrestrial ecosystem. This would provide a theoretical basis to defend against this highly invasive plant.

\section{Materials and methods}

\section{Study site}

The sampling site was located on the north shore of the Nanfei River in Hefei city, Anhui Province $\left(31.88^{\circ} \mathrm{N}, 117.26^{\circ} \mathrm{E}\right)$. The site belongs to a subtropical humid monsoon climate with annual average temperature of $15.8{ }^{\circ} \mathrm{C}$ and annual average rainfall of $995.3 \mathrm{~mm}$ with average annual sunshine of $1902.0 \mathrm{~h}$ (Yao et al., 2014). Along the plain of the river banks, the sampling sites are mainly located near the farmland (Fig. 1). According to vegetative ground cover rate (Niu et al., 2007; Chen et al., 2017). we established four rates of invasion by $A$. philoxeroides, that is, non-invaded $(\mathrm{O}, A$. philoxeroides number is 0 ), slightly invaded ( $\mathrm{S}$, A. philoxeroides accounted for $30 \%$ of individuals in each plot), moderately invaded (M, A. philoxeroides accounted for $60 \%$ of individuals in each plot) and heavily invaded (L, A. philoxeroides accounted for $>90 \%$ of individuals in each plot).

\section{Sample collection and processing}

From July to October 2016, soil samples were collected four times. For each rate of invasion 5 quadrats of $50 \mathrm{~cm} \times 50 \mathrm{~cm}$ were randomly selected; each sampling interval was more than $10 \mathrm{~m}$, and the natural environment was basically similar. The aboveground vegetation and litter was removed and soil was collected from 4 depths for each quadrat $(0-5,5-10,10-15$ and $15-20 \mathrm{~cm}$ ) by soil drilling (with a diameter of $7 \mathrm{~cm}$ ). Soil samples were placed into labelled ziplock bags before being taken back to the laboratory for analysis. At the same time, soil from the top $0-20 \mathrm{~cm}$ in each quadrat was collected and mixed well for analysis of soil physical and chemical properties. Identification of soil animals according to relevant literature (Yin, 1998).

Using the Tullgren method (Yin, 2002), soil animals were extracted in the laboratory using a funnel suspended above a $60 \mathrm{~W}$ light with continuous irradiation for at least 
$24 \mathrm{~h}$; the photopathic instinct of the soil animals makes them move away from the light into beakers containing $75 \%$ alcohol that are placed underneath the funnel. The soil animals were collected and classified under the optical microscope, and the number of individuals was recorded.

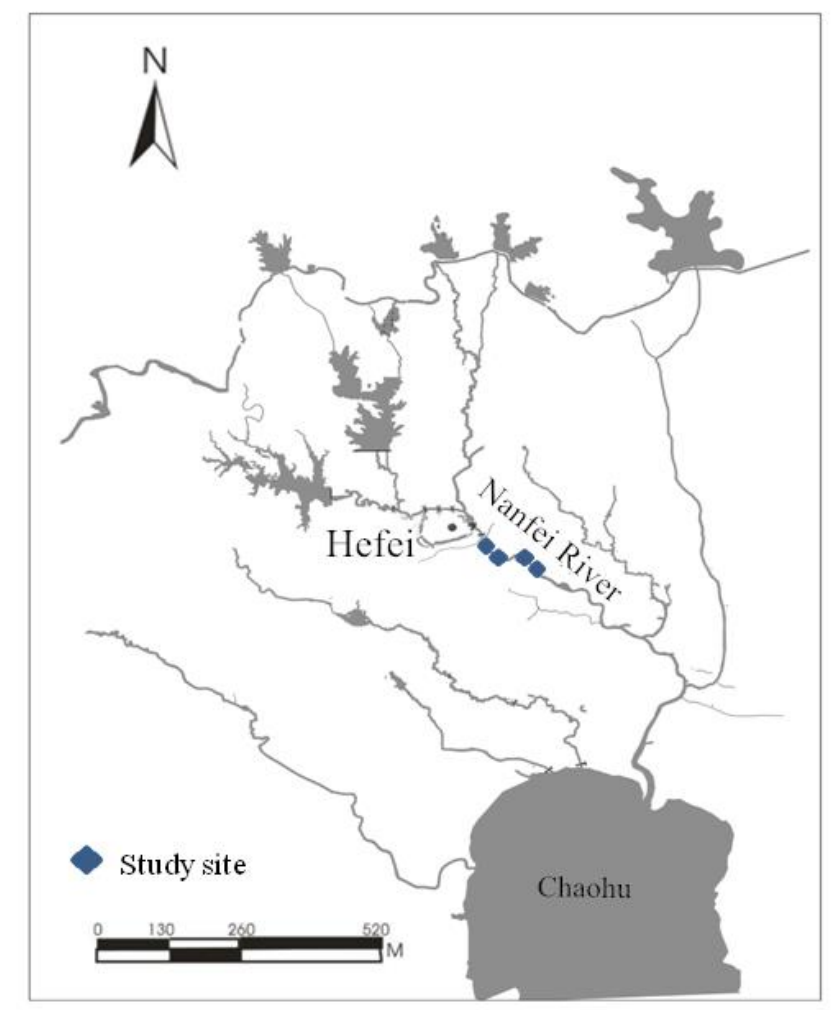

Figure 1. The sampling site is at Nanfeihe, Hefei, Anhui, China

Soil samples at depths of 0-5 cm, 5-10 cm, 10-15 cm and 15-20 cm were collected, and roots and stones were removed. Sufficient soil samples were taken by quartering method and air-dried in the room, and then ground through 40-mesh and 100-mesh soil sieves to make soil samples for the analysis of soil physical and chemical properties. Soil organic matter was assessed by potassium dichromate-sulfuric acid oxidation; soil total nitrogen was assessed by the Kjeldahl nitrogen method; soil total phosphorus and available phosphorus was determined by the Mo-Sb colorimetric method; total and available potassium content of soil were determined by flame photometry and soil moisture content measured by conventional drying and weighing method (Bao, 2000).

\section{Data analyses}

Diversity indices are usually used to determine the stability of a community or ecosystem; common indices include the Shannon-Wiener diversity index, Pielou's evenness index, Simpson's dominance diversity index and Margalef's richness index. The Shannon-Wiener index is an integrated indicator to measure richness and evenness. The community diversity of soil animals was analysed using the following indices:

$$
H^{\prime}=-\sum_{i=1}^{s} P_{i} \ln P_{i}
$$




$$
\begin{gathered}
E=H^{\prime} / \ln S \\
C=\sum\left(P_{\mathrm{i}}\right)^{2} \\
D=(S-1) / \ln N
\end{gathered}
$$

where $H^{\prime}$ is the Shannon-Wiener diversity index (Eq. 1); $E$ is Pielou's evenness index (Eq. 2); $C$ is the Simpson dominance index (Eq. 3); $D$ is the Margalef richness index (Eq. 4); $S$ is the number of species, $N$ is the total individual number of soil animals; and $P i$ is the proportion of individuals belonging to species $i$ in a sample.

All data were analysed using SPSS for Windows (SPSS, 20.0). Before the analysis, we conducted a diagnostic test of normal distribution and homoscedasticity, and the result is very satisfactory. Statistical analysis was performed by analysis of variance (one-way ANOVA and multiple comparison), and the means were subjected to the Duncan's multiple range test $(p<0.05)$ to obtain the main community differences between the treatments. In addition, to estimate the interaction of soil depth invasion degree among different degree of animal diversity was analyzed by two- way ANOVA analysis. SPSS's correlation analysis was used between soil animals species numbers and soil factors.

\section{Results}

\section{Impact of plant invasion on soil physicochemical properties}

The contents of soil organic carbon, total nitrogen, available potassium and available phosphorus in the heavily invaded areas were significantly higher than those in other plots (Table 1), The contents of available potassium and available phosphorus in the non-invaded area and the moderately invaded area were significantly lower than other treatments $(P<0.05)$, There was no significant difference in total phosphorus content between the four rates of invasion. The total potassium content was higher in the heavily and moderately invaded areas than in the other areas $(P<0.05)$, and there was no significant difference in total potassium content between the slightly invaded and non-invaded areas.

\section{Soil animal composition}

From four surveys, 2406 soil micro and meso-fauna were isolated, belonging to 7 classes, 13 orders and 25 families (Table 2). Among them, the dominant population (number of individuals accounting for more than $10 \%$ of the total number of individuals) consisted of acarina and collembola, accounting for $64.52 \%$ of the total amount of soil animals captured; common components of the population (individuals accounting for $1 \%$ to $10 \%$ of the total individuals) could be classified into nine categories: Diptera, Isopoda, Hymenoptera, Diplura, Psocoptera, nematodes, Haplotaxida, Geophilella and Pauropus, accounting for $32.51 \%$ of the total amount of soil animals captured. The rest of the individuals captured were rare populations (individuals accounting for $1 \%$ of the total number of individuals), accounting for $2.97 \%$ of the total amount of soil animals captured. From slight intrusion area to heavily intrusion area, total individual number of soil animals showed the trend of first increased and then decreased, number of species tends to be stable. 
Table 1. Effects of A. philoxeroides invasion on soil chemical and physical properties

\begin{tabular}{c|c|c|c|c|c|c|c}
\hline & $\begin{array}{c}\text { Organic } \\
\mathbf{m a t t e r} \\
(\mathbf{g} / \mathbf{k g})\end{array}$ & $\begin{array}{c}\text { Total N } \\
(\mathbf{g} / \mathbf{k g})\end{array}$ & $\begin{array}{c}\text { Total P } \\
(\mathbf{g} / \mathbf{k g})\end{array}$ & $\begin{array}{c}\text { Total K } \\
(\mathbf{g} / \mathbf{k g})\end{array}$ & $\begin{array}{c}\text { Available K } \\
(\mathbf{m g} / \mathbf{k g})\end{array}$ & $\begin{array}{c}\text { Moisture } \\
\text { content (\%) })\end{array}$ & $\begin{array}{c}\text { Available P } \\
(\mathbf{m g} / \mathbf{k g})\end{array}$ \\
\hline $\mathrm{O}$ & $6.8 \pm 0.67 \mathrm{~d}$ & $0.5 \pm 0.03 \mathrm{~b}$ & $0.2 \pm 0.04 \mathrm{ab}$ & $16.7 \pm 0.36 \mathrm{c}$ & $176.0 \pm 1.73 \mathrm{~d}$ & $0.26 \pm 0.03 \mathrm{~b}$ & $10.9 \pm 1.47 \mathrm{c}$ \\
$\mathrm{S}$ & $19.6 \pm 0.64 \mathrm{c}$ & $1.1 \pm 0.11 \mathrm{c}$ & $0.2 \pm 0.02 \mathrm{~b}$ & $16.0 \pm 0.10 \mathrm{c}$ & $188.7 \pm 0.58 \mathrm{c}$ & $0.23 \pm 0.01 \mathrm{~b}$ & $18.1 \pm 2.23 \mathrm{~b}$ \\
$\mathrm{M}$ & $23.4 \pm 0.73 \mathrm{~b}$ & $1.2 \pm 0.05 \mathrm{~b}$ & $0.3 \pm 0.03 \mathrm{a}$ & $17.8 \pm 0.85 \mathrm{~b}$ & $217.7 \pm 7.09 \mathrm{~b}$ & $0.28 \pm 0.01 \mathrm{~b}$ & $19.5 \pm 1.86 \mathrm{ab}$ \\
$\mathrm{L}$ & $29.0 \pm 0.74 \mathrm{a}$ & $1.7 \pm 0.10 \mathrm{a}$ & $0.2 \pm 0.06 \mathrm{ab}$ & $19.5 \pm 0.44 \mathrm{a}$ & $300.3 \pm 0.58 \mathrm{a}$ & $0.39 \pm 0.06 \mathrm{a}$ & $22.3 \pm 2.76 \mathrm{a}$ \\
\hline
\end{tabular}

Values are mean \pm SD. Different letters in the same column indicate that means are significantly different at $\mathrm{P}<0.05 .(\mathrm{a}>\mathrm{b}>\mathrm{c}) \mathrm{O}$ : non-invaded area, $\mathrm{S}$ : slight invaded area, M: moderate invaded area, L: heavily invaded area

Table 2. The richness and abundance of soil fauna in different A. philoxeroides invasion area

\begin{tabular}{|c|c|c|c|c|c|c|c|c|c|c|}
\hline & \multicolumn{2}{|c|}{ Non-invaded } & \multicolumn{2}{|c|}{$\begin{array}{c}\text { Slight } \\
\text { invaded }\end{array}$} & \multicolumn{2}{|c|}{$\begin{array}{l}\text { Moderate } \\
\text { invaded }\end{array}$} & \multicolumn{2}{|c|}{$\begin{array}{l}\text { Heavily } \\
\text { invaded }\end{array}$} & \multicolumn{2}{|c|}{ Total } \\
\hline & $\mathbf{N}$ & $\%$ & $\mathbf{N}$ & $\%$ & $\mathbf{N}$ & $\%$ & $\mathbf{N}$ & $\%$ & $\mathbf{N}$ & $\%$ \\
\hline \multicolumn{11}{|l|}{ Parasiformes } \\
\hline Ixodidae & 159 & 6.61 & 132 & 5.49 & 204 & 8.48 & 183 & 7.61 & 678 & 28.18 \\
\hline \multicolumn{11}{|l|}{ Acariformes } \\
\hline Chigger mites & 6 & 0.25 & 12 & 0.5 & 6 & 0.25 & 0 & 0 & 24 & 1 \\
\hline Oribatulidae & 78 & 3.24 & 72 & 2.99 & 111 & 4.61 & 102 & 4.24 & 363 & 15.09 \\
\hline \multicolumn{11}{|l|}{ Diptera } \\
\hline Muscidae & 24 & 1 & 36 & 1.5 & 30 & 1.25 & 36 & 1.5 & 126 & 5.24 \\
\hline Chironomidae & 0 & 0 & 0 & 0 & 0 & 0 & 3 & 0.12 & 3 & 0.12 \\
\hline \multicolumn{11}{|l|}{ Collembola } \\
\hline Isotomidae & 39 & 1.62 & 78 & 3.24 & 105 & 4.36 & 87 & 3.62 & 309 & 12.84 \\
\hline Folsomides & 0 & 0 & 0 & 0 & 6 & 0.25 & 3 & 0.12 & 9 & 0.37 \\
\hline Entomobrya & 18 & 0.75 & 30 & 1.25 & 48 & 2 & 45 & 1.87 & 141 & 5.86 \\
\hline Sminthuridae & 6 & 0.25 & 6 & 0.25 & 9 & 0.37 & 0 & 0 & 21 & 0.87 \\
\hline Onychiuridae dinghuensis & 6 & 0.25 & 12 & 0.5 & 15 & 0.62 & 3 & 0.12 & 36 & 1.5 \\
\hline \multicolumn{11}{|l|}{\begin{tabular}{c|} 
Isopoda \\
\end{tabular}} \\
\hline Porcellio & 3 & 0.12 & 45 & 1.87 & 21 & 0.87 & 24 & 1 & 93 & 3.87 \\
\hline \multicolumn{11}{|l|}{ Hymenoptera } \\
\hline Aenictus & 12 & 0.5 & 57 & 2.37 & 42 & 1.75 & 21 & 0.87 & 132 & 5.49 \\
\hline \multicolumn{11}{|l|}{ Coleoptera } \\
\hline Family Nitidulidae & 0 & 0 & 0 & 0 & 0 & 0 & 3 & 0.12 & 3 & 0.12 \\
\hline Staphylinidae & 3 & 0.12 & 6 & 0.25 & 3 & 0.12 & 0 & 0 & 12 & 0.5 \\
\hline \multicolumn{11}{|l|}{ Corrodentia } \\
\hline $\begin{array}{c}\text { Psocidae } \\
\text { Entotrophi }\end{array}$ & 54 & 0.75 & 54 & 0.37 & 39 & 1.62 & 57 & 2.37 & 123 & 5.11 \\
\hline $\begin{array}{c}\text { Japygidae } \\
\text { Thysanoptera }\end{array}$ & 0 & 0 & 3 & 0.12 & 3 & 0.12 & 0 & 0 & 6 & 0.25 \\
\hline Thripidae & 6 & 0.25 & 18 & 0.75 & 0 & 0 & 0 & 0 & 24 & 1 \\
\hline
\end{tabular}




\begin{tabular}{|c|c|c|c|c|c|c|c|c|c|c|}
\hline \multicolumn{11}{|l|}{ Plecoptera } \\
\hline Perlidae larvae & 3 & 0.12 & 3 & 0.12 & 3 & 0.12 & 0 & 0 & 9 & 0.37 \\
\hline \multicolumn{11}{|l|}{ Hemiptera } \\
\hline Pentatomidae & 0 & 0 & 6 & 0.25 & 0 & 0 & 0 & 0 & 6 & 0.25 \\
\hline \multicolumn{11}{|l|}{ Pseudoscorpionida } \\
\hline Chthonioidea & 3 & 0.12 & 0 & 0 & 0 & 0 & 0 & 0 & 3 & 0.12 \\
\hline \multicolumn{11}{|l|}{ Strongylida } \\
\hline Meloidogynidae & 0 & 0 & 21 & 0.87 & 45 & 1.87 & 18 & 0.75 & 84 & 3.49 \\
\hline \multicolumn{11}{|l|}{ Araneae } \\
\hline Arachnid & 3 & 0.12 & 3 & 0.12 & 12 & 0.5 & 6 & 0.25 & 24 & 1 \\
\hline \multicolumn{11}{|l|}{ Others } \\
\hline Scolopendrellidae & 15 & 0.62 & 15 & 0.62 & 36 & 1.5 & 21 & 0.87 & 87 & 3.62 \\
\hline Haplotaxis & 0 & 0 & 6 & 0.25 & 9 & 0.37 & 54 & 2.12 & 66 & 2.74 \\
\hline Pauropus & 0 & 0 & 6 & 0.25 & 3 & 0.12 & 15 & 0.62 & 24 & 1 \\
\hline Total individuals & 402 & 16.71 & 576 & 23.94 & 750 & 31.17 & 678 & 28.18 & 2406 & \\
\hline Total species & 17 & & 21 & & 21 & & 17 & & 27 & \\
\hline
\end{tabular}

$\mathrm{N}$ : the number of individuals, \%: representing the percentage of the total number of individuals

\section{Community diversity of soil fauna under different rates of A. philoxeroides invasion}

In the different degree of invasion of Alternanthera philoxeroides, there are some differences in community structure in soil animal (Fig. 2). The Margalef richness index was not significantly different $(p<0.05)$ among the four rates of invasion, but the Simpson dominance index $(p<0.05)$ in the non-invaded area was significantly different from those in the other three areas, and Shannon-Wiener diversity index space significant difference $p<0.05$ ) In the non-invaded communities, soil animals are less and the number of species are relatively concentrated; In the A. philoxeroides invaded communities, There was no significant difference between the slight intrusion to heavily invasion areas, but the Simpson's dominance diversity index increased with the increase of the invasion degree, indicating A. philoxeroides invasion may affect to some extent of soil animal community, and in moderate intrusion conditions most suitable soil animal survival.

\section{Community diversity of soil fauna at different soil depth}

In the vertical direction, the number of species and individual density of soil animals showed a tendency of obvious aggregation, decreasing with the increase of soil depth. For all treatments, the number of individuals and species of soil animals was highest in the $0-5 \mathrm{~cm}$ soil layer and lowest in the $15-20 \mathrm{~cm}$ soil layer, although there was no obvious trend in the $5-15 \mathrm{~cm}$ soil layer (Fig. 3).

The Shannon-Wiener diversity index and Pielou's evenness index showed no significant difference with depth (Fig. 4), although they increased with increasing soil depth. The Simpson index was significantly different in the $15-20 \mathrm{~cm}$ soil layer when compared with the other soil layers $(P<0.05)$, but the Shannon-Wiener and Margalef indices were the lowest at this depth, indicating that as the soil depth increased, species 
diversity decreased, but there were some dominant species that adapted to the deep soil environment and were uniformly distributed.
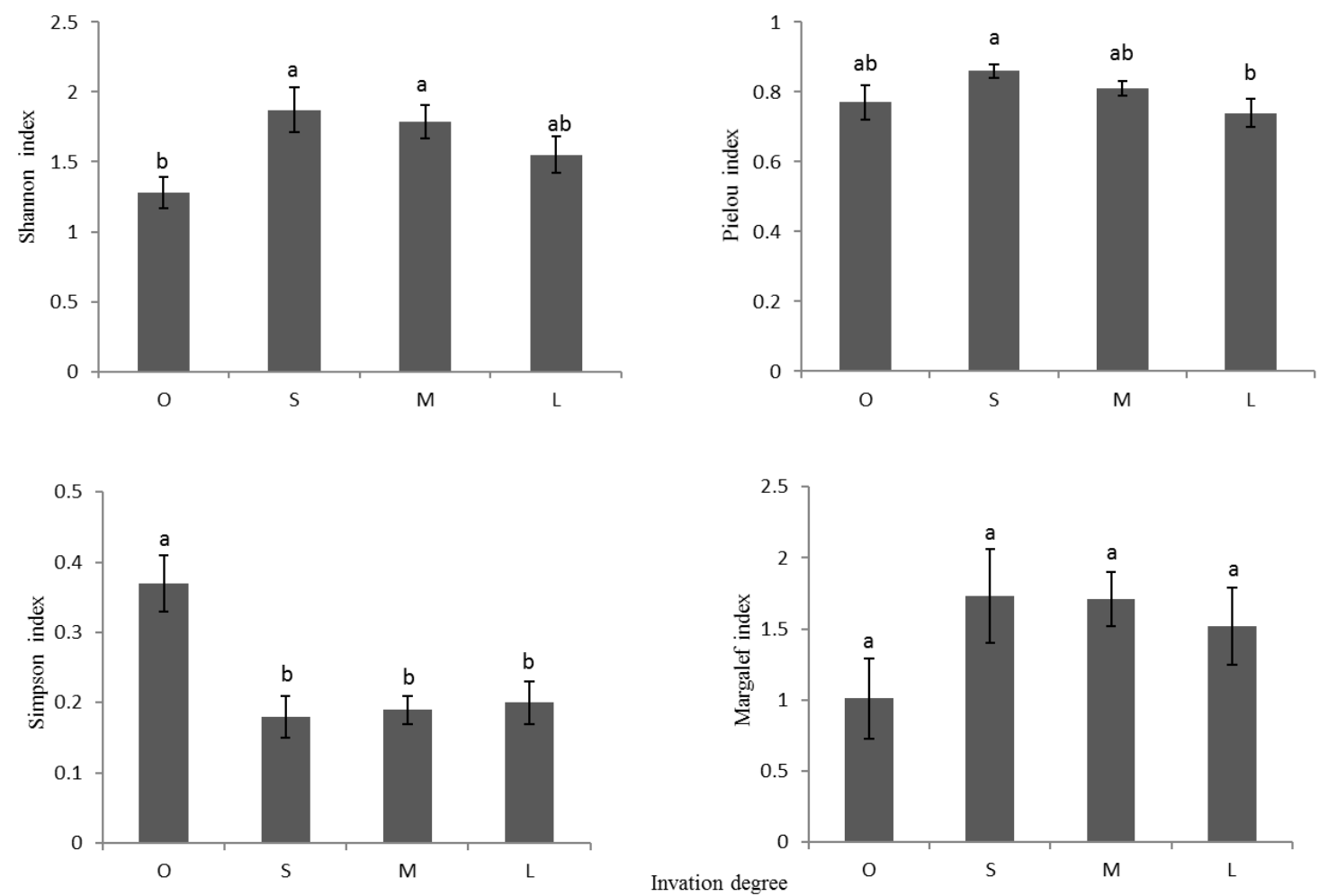

Figure 2. Diversities of soil fauna community in in different A. philoxeroides invasion area (mean $\pm S E$ ). (Different letters indicate that means are significantly different at $P<0.05$ with $a>b>c$; O: non-invaded area, S: slight invaded area M: moderate invaded area, L: heavily invaded area)

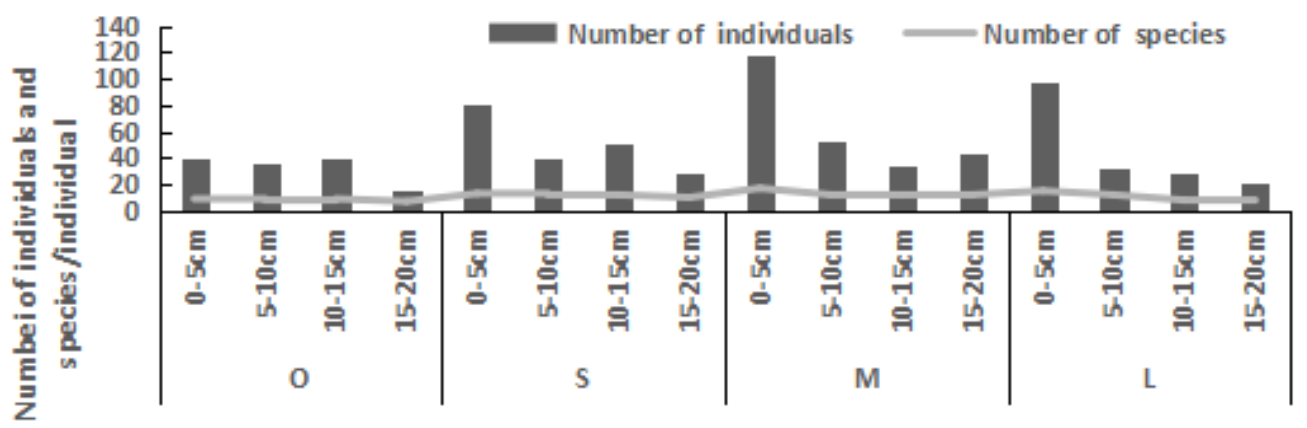

The invasion of conditions

Figure 3. Vertical distribution of the group number and individual number of soil fauna in different invasion area

\section{Different invasion degree and soil depth on soil animals community structure parameters}

The two-way analysis of variance of invasion and depth and community showed that the degree of invasion has significant influence on community diversity $(P<0.05)$. Soil 
depth of different degree of invasion has significant effects on community diversity $(P<0.01)$, and significant impact on the community dominance index and evenness. he distribution of soil animals was affected by the rate of invasion and soil depth but no significant effect of the two factor interactions on the four community structure indices (Table 3). And the rate of invasion and soil depth were respectively affecting four indicators of diversity rather than a common effect.
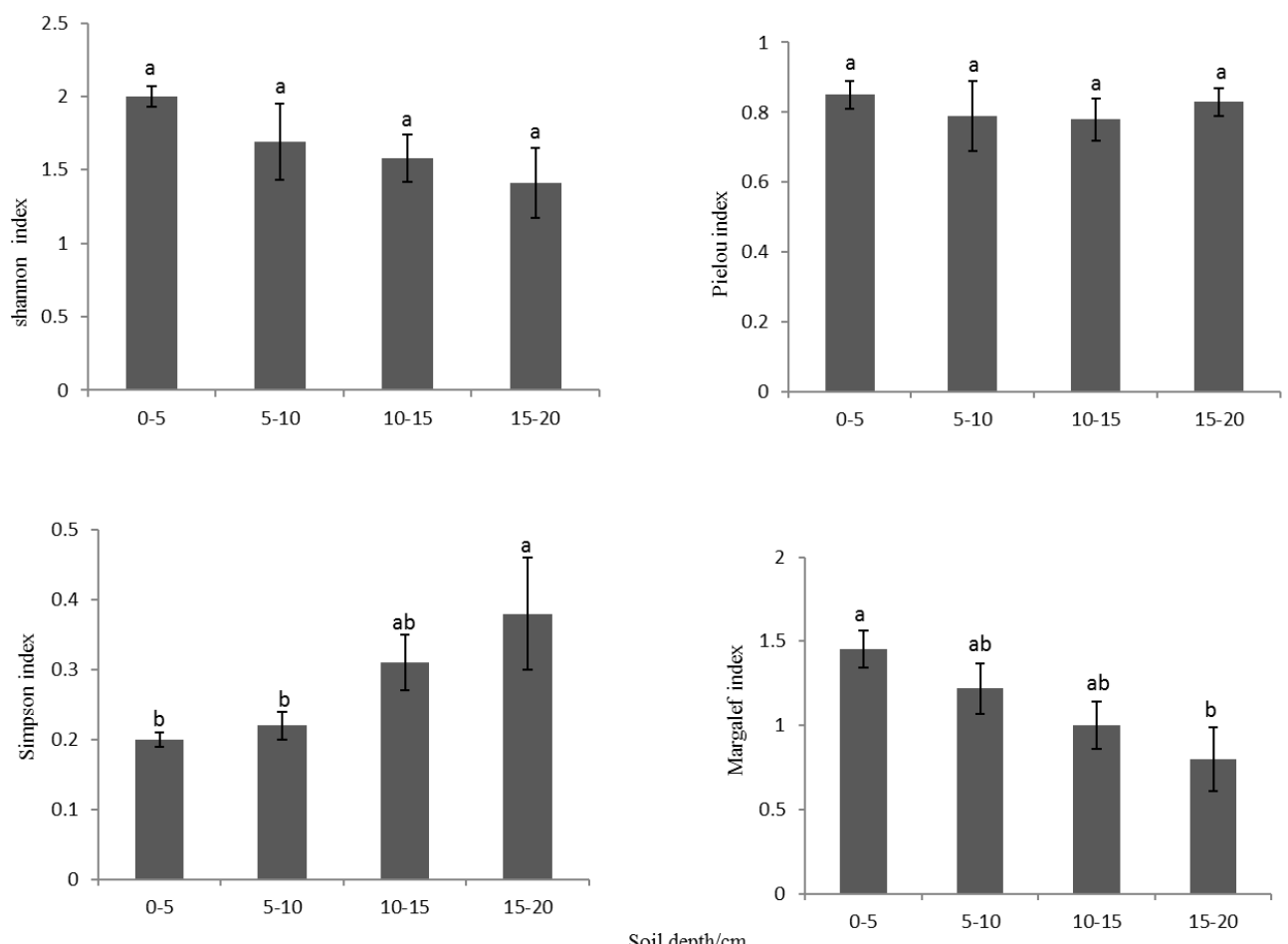

Figure 4. Diversities of soil fauna community in different soil depth (mean $\pm S E$ ). (Different letters indicate that means are significantly different at $P<0.05$ with $a>b>c$ )

Table 3. F-values of a two-way analysis of variance of soil animals community structure parameters in different invasion area and soil depth

\begin{tabular}{c|c|c|c|c|c}
\hline \multirow{2}{*}{ Variable } & \multirow{2}{*}{ DF } & Shannon-Wiener & Pielou & Simpson & Margalef \\
\cline { 3 - 6 } & & $\mathbf{F}$ & $\mathbf{F}$ & $\mathbf{F}$ & $\mathbf{F}$ \\
\hline Invasion degree & 3 & $0.963^{*}$ & 2.657 & 0.321 & 0.617 \\
Depth & 3 & $5.214 * *$ & 1.629 & $13.187 *$ & $24.294 *$ \\
Invasion * depth & 9 & 0.366 & 0.927 & 0.68 & 0.889 \\
\hline
\end{tabular}

*Correlation is significant at the 0.05 level. $* *$ Correlation is significant at the 0.01 level

\section{The relationship between soil physicochemical properties and soil animals in $A$. philoxeroides invaded areas}

The correlation of soil animals species and soil physical and chemical properties under different rates of invasion is shown in Table 4. Except for the non-invasive area (O area), the number of soil animal species in the invaded area (, M, L) was significantly negatively correlated with total potassium indicating that the distribution 
of soil animals was greatly influenced by total potassium content. The number of species in the slightly invaded area $(S)$ was significantly correlated with total phosphorus $(P<0.01)$, but this relationship was not observed in other treatments (Table 4). The total potassium content increased significantly from the non-invaded area to the severely invaded area $(P<0.05)$. When comparing the numbers of individuals and species of soil animals in different invaded areas (Fig. 3), it was found that for both moderately and severely invaded areas, the numbers of soil fauna individuals and species were closely aligned with the total potassium distribution, further indicating that the distribution of soil animals might be affected by the total potassium content.

Table 4. Correlations between soil animals species numbers and soil factors

\begin{tabular}{c|c|c|c|c|c|c}
\hline & Organic matter & Total N & Total P & Total K & Available P & Available K \\
\hline $\mathrm{O}$ & 0.11 & 0.30 & 0.17 & -0.22 & -0.31 & 0.22 \\
$\mathrm{~S}$ & 0.05 & 0.32 & $0.71^{* *}$ & $-0.43^{*}$ & -0.24 & 0.02 \\
$\mathrm{M}$ & 0.34 & 0.30 & 0.48 & $-0.56^{*}$ & -0.28 & 0.23 \\
$\mathrm{~L}$ & 0.44 & 0.61 & 0.37 & $-0.11^{*}$ & -0.41 & 0.42 \\
\hline
\end{tabular}

$* * \mathrm{P}<0.01 ; * \mathrm{P}<0.05$

\section{Discussion}

\section{Effect of A. philoxeroides on the soil faunal community}

The present study showed that with the increasing rate of invasion, the total number of individuals and groups of soil meso-and microfauna increased first and then decreased, and the number of individuals and species in some soil animals increased (Table 2). These results are consistent with those of several other studies: Gremmen (1998) found that communities dominated by exotic plants the grass Agrostis stolonifera have more soil invertebrates and mites at sub-Antarctic Marion Island; Kourtev (2002) found that the number of earthworms in invaded areas was significantly increased when compared with native plant communities; Quan et al. (2011) found that Mikania micrantha invasion significantly increased the number of soil nematodes and Acarina individuals, community density and the number of groups in the Huolushan Forest Park of Guangzhou, China; Xie et al. (2011) through found that ragweed invasion significantly increased the density of the community-group numbers of soil fauna, Simpson index and Margalef index by the field plot test method in the suburb of Lishi Town, Shaoguan City, Guangdong Province. These results showed the same results about that invasion by exotic plants can increase the biomass or diversity of soil animals.

A. philoxeroides is an amphibious herbaceous plant with strong adaptive and reproductive ability. Chang et al. (2013) research showed that it can quickly form a carpet cover distribution in the invaded area and change the local microclimate environment and soil physical and chemical properties. With the increasing rate of invasion, the soil water content increased and the environmental conditions were more conducive to hygrocoles such as Nematodes, Mites and Collembola. Soil animals feed on plant humus, radicle and caulicle, Alkemade et al. (2015) showed that after Spartina anglica invasion of the European coastal wetland, because of its high net primary productivity, the decomposition of a large number of aging stems provided additional resources into the detritus food web, leading to an increase in the number of soil invertebrates. The development of A. philoxeroides roots and stems can provide an 
abundant food source for soil animals (Pan et al., 2007). In our study, with the increasing rate of invasion by $A$. philoxeroides, the number of hygrophilous Acarina and Collembola drastically increased, and the biomass of the moderately invaded area was the highest, with slightly less biomass in the severely invaded area (Table 2). It could be due to the high vegetation coverage, environmental conditions are changed, such as increased humidity and poor ventilation, thus resulting in the disappearance of Thysanoptera, Plecopterodae, Hymenoptera, Hemiptera and other stomatal breathing soil animals, and a significant increase in the number of hygrophilous animals like Earthworms. Siersma et al. (2007) also suggested that invasive plant covers may lead to the changes of soil animals' number, but more research is also necessary to support the major claims of this study.

\section{Effect of A. philoxeroides invasion on soil fauna diversity indices}

It can be found in the study: with increasing rate of invasion, the Shannon-Wiener, Pielou and Margalef indices decreased, while the Simpson index increased, indicating that although invasion increased the biomass of small and medium-sized soil animals, the diversity, in terms of the number of groups, decreased, indicating that the increase in abundance of soil fauna was concentrated within a small number of groups, such as Parasiforme, Acariformes and Collembola (Table 2).

Many studies have shown that the density of soil animals decreases with depth, with the majority of soil fauna distributing in the top $0-5 \mathrm{~cm}$ and significant reductions in number and diversity in deeper soil (Fig. 3), for example, Chen and Aoki (1998) surveyed the distribution of soil mites in different soil layers in Changchun and found that the amount and type of mites in the soil layer vertical structure was sharply reduced with increasing soil depth, plummeted with the result what Aoki survey mites distribution in the soil layers $(0-5) \mathrm{cm}$ highest plummeted down) coincide. Yin et al. (2003a) studied the diversity of soil fauna in the Lesser Khingan forest and found that diversity in vertical direction of soil animals decreased with soil depth and that the surface aggregation of soil meso-and micro arthropods was more obvious than that of large soil animals. Similar results were found in our study, where the vertical distribution of soil fauna in both invaded and non-invaded areas was highest in the $0-5$ $\mathrm{cm}$ soil layer and decreased with increasing soil depth (Fig. 3).

\section{Effects of soil physicochemical properties on the distribution of soil fauna}

There is a close relationship between soil animals and soil environmental factors. Some studies have shown that the soil environmental factors have little effect on the animal groups, just concerning with the number of individual soil animals (Kourtev et al., 1999; Yin et al., 2003b). But in our studies found that A. philoxeroides invasion influencing the soil physico-chemical properties, with increasing rate of invasion, soil organic carbon, total nitrogen, available phosphorus, available potassium and total potassium contents increased, there was a significant negative correlation between soil total potassium and the number of soil animal groups $(P<0.05)$, with the increase of total potassium in soil, the soil fauna decreased, it indicated that the regulation of soil potassium content may change the diversity of soil animal communities. Similar results have been found in invasive plants such as Ambrosia artemisiifolia, Solidago canadensis and Ageratina adenophora (Cruz-Ortega et al., 1998; Tan et al., 2002; Zhang, et al., 2009). 


\section{Conclusion}

In summary, changes in the soil faunal diversity indices with different rates of invasion and soil depth showed that A. philoxeroides invasion affects the species and quantity distribution of small and medium-sized soil animals. Among the communities invaded by $A$. philoxeroides, the Acarina and the Collembola were dominant members of the population. Soil animals communities were mainly distributed in the topsoil with high vegetation coverage rate and rich humus and litter, presenting a decreasing trend in abundance in the vertical direction under the common constraints of multiple environmental factors and climate conditions. In the future, comprehensive research on soil animals in A. philoxeroides should be strengthened to improve the invasion mechanism. Provide a theoretical basis for better prevention and control of invasive species.

Acknowledgments. This study was supported by the National Key Research and Development Program (2017YFD0200604); the National Natural Science Foundation of China under grant (31772235,31540051); State Key Laboratory for Biology of Plant Diseases and Insect Pests under grant (SKLOF201605). The experiments reported in this paper comply with the current laws of the People's Republic of China where they were conducted.

Conflict of interests. All of the authors in this paper declare that they have no conflict of interests.

\section{REFERENCES}

[1] Alkemade, R., Wielemaker, A., Hemminga, M. A. (2015): Correlation between nematode abundance and decomposition rate of Spartina anglica leaves. - Marine Ecology Progress 99(3): 293-300.

[2] Belnap, J., Phillips, S. L. (2001): Soil biota in an ungrazed grassland: response to annual grass (Bromus tectorum) invasion. - Ecological Applications 11(5): 12611275.

[3] Bao, S. D. (2000): Soil Agrochemical Analysis. - China Agriculture Press, Beijing.

[4] Chang, R. Y., Wang, R. Q., Zhang, Y. R., Liu, J. (2013): Invasion mechanism and integrated management of invasive plant Alternanthera philoxeroides. - Journal of Ecology and Rural Environment 29(1): 17-23.

[5] Chen, P. G., Aoki, J. (1998): Investigation on soil acarid in Jingyuetan area Changchun. - Acta Zoologica Sinica 34(3): 282-293.

[6] Chen, X. L., Zhang, L. N., Wang, J. H., et al. (2017): Effect of invasive degree of Rhynchelytm repens on microorganisms in rhizosphere soil. - Natural Science Edition 45(4): 165-172.

[7] Cruz-Ortega, R., Anaya, A. L., Hernández-Bautista, B. E., Laguna-Hernández, G. (1998): Effects of allelochemical stress produced by Sicyos deppei, on seedling root ultrastructure of Phaseolus vulgaris, and Cucurbita ficifolia. - Journal of Chemical Ecology 24(12): 2039-2057.

[8] Ding, X., Zhang, Y., Zhu, Y. H., et al. (2017): Advances in spatial distribution and influencing factors of soilanimal population. - Hunan Agricultural Sciences 1: 119122.

[9] Fernández, F. M., Gómez, R. M. X., González, P. S. J. (2015): Effects of fire and three fire-fighting chemicals on main soil properties, plant nutrient content and vegetation growth and cover after 10 years. - Science of the Total Environment 515516: $92-100$. 
[10] Gremmen, N., Chown, S. L., Marshall D. J. (1998): Impact of the introduced grass Agrostis stolonifera on vegetation and soil fauna communities at Marion Island, subAntarctic. - Biological Conservation 85(3): 223-231.

[11] Guo, H., Mazer, S. J., Xu, X., Luo, X., Huang, K., Xu, X. (2017): Biological Invasions in Nature Reserves in China. - In: Wan, F., Jiang, M., Zhan, A. (eds.) Invading Nature. Springer Series in Invasion Ecology. Springer, Dordrecht.

[12] Kourtev, P. S., Huang, W. Z., Ehrenfeld, J. G. (1999): Differences in earthworm densities and nitrogen dynamics in soils under exotic and native plant species. Biological Invasions 1: 237-245.

[13] Kourtev, P. S., Ehrenfeld, J. G., Haggblom, M. (2002): Exotic plant species alter the microbial community structure and function in the soil. - Ecology 83(11): 3152-3166.

[14] Nicola, J. D., Pedro, M. A., Kari, E. D. (2015): Changes in arbuscular mycorrhizal fungal communities during invasion by an exotic invasive plant. - Acta Oecologica 67: 66-74.

[15] Niu, H. B., Liu, W. X., Wan, F. H. (2007): Invasive effect of Ageratina adenophora Sprengel (Asteraceae) on soil microbial community and physical and chemical properties. - Acta Ecology Sinica 27(7): 3051-3060.

[16] Pablo, S. A., Ana, N., Luís, G. (2014): Soil biochemical alterations and microbial community responses under Acacia dealbata Link invasion. - Soil Biology \& Biochemistry 79: 100-108.

[17] Pan, X. Y., Geng, Y. P., Sosa, A. (2007): Invasive alternanthera philoxeroides: biology, ecology and management. - Acta Phytotaxonomica Sinica 45(6): 884-900.

[18] Quan, G. M., Liu, W. X., Xie, J. F., et al. (2011): Impact of Mikania micrantha invasion on soil meso- and micro-invertebrate community structure. - Chinese Journal of Applied Ecology 22(7): 1863-1870.

[19] Shao, Y. H., Zhang, W. X., Liu, S. J. (2015): Diversity and function of soil fauna Acta Ecologica Sinica 35(20): 6614-6625.

[20] Siersma, H., Johnson, W., Mckeon, V. (2007): The effect of invasive plant species on invertebrate biodiversity in Great Lakes coastal wetlands. - ResearchGate 8: 15.

[21] Tan, W. Z., Li, Q. J., Qing, L. (2002): Biological control of alligator weed (Alternanthera philoxeroides) with a Fusarium sp. - Biocontrol (Dordrecht) 47(4): 463-479.

[22] Van Driesche, R., Blossey, B., Reardon, R. (2002): Biological Control of Invasive Plants in the Eastern United States. - Forest Health Technology Enterprise Team, USDA Forest Service, Morgantown.

[23] Xiang, C. G., Yang, S. J., Nie, Q. (2007): The biological indication of soil animals to soil. - Environment Chinese Agricultural Science Bulletin 23(04): 364-367.

[24] Xie, J. F., Quan, G. M., et al. (2011): Impacts of Ambrosia artemisia folia invasion on community structure of soil meso-and micro-fauna. - Acta Ecologica Sinica 31(19): $5682-5690$.

[25] Yao, X. Y., Wei-Tao, L. I., Zheng, Y. L. (2014): Effect of community composition and species interactions on the invasion of alien plants. - Chinese Journal of Ecology 33(7): 1953-1959.

[26] Yin, W. Y. (1998): Chinese Soil Animal Search Illustrations. - Science Press, Beijing.

[27] Yin, W. Y. (2000): Soil animal of China. - Science Press, Beijing.

[28] Yin, X. Q., Ma, Z. Y. (2002): Efficiency of Tullgren method to middle-small-sized soil animal. - Journal of Northeast Normal University 34: 84-91.

[29] Yin, X. Q., Wu, D. H., Han, X. M. (2003a): Diversity of soil animals community in Xiao Hinggan Mountains. - Scientia Geographica Sinica 23(03): 316-322.

[30] Yin, X. Q., Wang, H. X., Zhou, D. W. (2003b): Characteristics of soil animals' communities in different agricultural ecosystem in the Songnen Grassland of China. Acta Ecology Sinica 23(6): 1071-1078. 
[31] Yu, W. Q., Liu, W. X., Gui, F. R., et al. (2012): Invasion of exotic Ageratina adenophora Sprengel alters soil physical and chemical characteristics and arbuscular mycorrhizal fungus community. - Acta Ecologica Sinica 32(22): 114-122.

[32] Zhang, Z., Xu, L., Ma, Y. T., Li, J. (2009): Allelopathic effect of water extracts from the different organizations of Alternanthera philoxeroides on germination and seedling growth of Lolium perenne. - Acta Botanica Boreali - Occidentalia Sinica 29(1): 148-153.

[33] Zhou, F., Zhang, Z. J., Liu, M., et al. (2017): Effects of nutrient levels on defense against specialist insects in an invasive alligator weed. - Biodiversity Science 25(12): 1276-1284. 